\title{
Гидрогеохимический мониторинг разработки нефтяной залежи горизонта Ю 1 Верх-Тарского месторождения (Западная Сибирь)
}

\author{
Новиков Д.А. ${ }^{1,2}$, Павлова С.А. ${ }^{3}$, Рыжкова С.В. ${ }^{1,2}$, Фаустова А.С. ${ }^{2}$, Черников А.А. ${ }^{2}$, Дульцев Ф.Ф. ${ }^{1}$, \\ Черных А.В. ${ }^{1}$ \\ ${ }^{1}$ Институт нефтегазовой геологии и геофизики им. А.А. Трофимука СО РАН, Новосибирск, \\ NovikovDA@ipgg.sbras.ru \\ ${ }^{2}$ Новосибирский национальный исследовательский государственный университет, Новосибирск \\ ${ }^{3} \mathrm{AO}$ «Новосибирскнефтегаз», Новосибирск
}

\begin{abstract}
Аннотация. Впервые приводятся результаты обобщения данных по геохимии подтоварных вод и гидрогеохимическому мониторингу разработки нефтяной залежи продуктивного горизонта Ю Верх-Тарского месторождения, расположенного на северо-западе Новосибирской области. В настоящее время подтоварные воды имеют хлоридный натриевый состав с величиной общей минерализации от 24.7 до 48.9 г/дм³. При вводе в промышленную разработку в качестве агента заводнения для системы поддержания пластового давления выступали воды апт-альб-сеноманского водоносного комплекса. Затем, при росте обводненности продукции добывающего фонда скважин стали использовать подтоварные воды по замкнутому циклу. С 2019 года для повышения нефтеотмывающей способности агента заводнения для закачки в систему ППД наряду с подтоварными водами стали применять попутно добываемые рассолы палеозойского водоносного комплекса Малоичского нефтяного месторождения.
\end{abstract}

Ключевые слова: подтоварные воды, гидрогеохимический мониторинг, разработка, продуктивный горизонт $Ю_{1}$, Верх-Тарское нефтяное месторождение, Западная Сибирь.

\section{Hydrogeochemical monitoring of the $\mathrm{Yu}_{1}$-horizon development at the Verkh-Tarsk oil field (south of West Siberia)}

\author{
Novikov D.A. ${ }^{1,2}$, Pavlova S.A. ${ }^{3}$, Ryzhkova S.V. ${ }^{1,2}$, Faustova A.S. ${ }^{2}$, Chernikov A.A. ${ }^{2}$, Dultsev F.F. ${ }^{1}$, \\ Chernykh A.V. ${ }^{1}$ \\ ${ }^{\prime}$ Trofimuk Institute of Petroleum Geology and Geophysics of SB of RAS, Novosibirsk, NovikovDA@ipgg.sbras.ru \\ ${ }^{2}$ Novosibirsk State University, Novosibirsk \\ ${ }^{3}$ Joint-stock company «Novosibirskneftegaz», Novosibirsk
}

\begin{abstract}
Results obtained by summarizing the data on the geochemistry of off-spec waters and on the hydrogeochemical monitoring of the development of the oil pool in the $\mathrm{Yu}_{1}$ productive horizon of the Verkh-Tara deposit situated in the north-west of the Novosibirsk Region are reported for the first time. At present, the off-spec waters have sodium chloride composition with total mineralization from 24.7 to $48.9 \mathrm{~g} / \mathrm{dm}^{3}$. At the start-up of the commercial development, waters of the Aptian-Albian-Cenomanian aquifer system were used as the flooding agent for the reservoir pressure maintenance system. Then, with an increase in water influx in the production well stock, the use of bottoms waters in the closed cycle was introduced. Since 2019, in order to enhance the oil flushing capacity of the flooding agent, brines produced from the Paleozoic aquifer system of the Maloich oil deposit are used along with the off-spec waters for pumping into the reservoir pressure maintenance system.

Key words: off-spec water, hydrogeochemical monitoring, development, productive horizon $\mathrm{Yu}_{1}$, VerkhTarskoye oil field, Western Siberia.

Современные методы нефтегазопромысловой гидрогеохимии базируются на многих теоретических положениях естествознания. Огромное значение, в частности, имеют фундаментальные труды Д.И. Менделеева, Я.Х. Вант-Гоффа, Д.Д. Томсона, Р.Ю. Клаузиуса, С.А. Аррениуса, Д.У. Гиббса, Г.И. Гесса по термодинамике и кинетике электролитов. Гидрохимические исследования в процессе контроля разработки нефтяных и газовых месторождений проводятся с 1960-х годов. Это связано не только с практическими выгодами гидрогеохимического мониторинга (дешевизна, простота производственных операций и химических анализов), но и с его высокой информативностью, обеспеченной геохимической сущностью техногенеза, способностью пластовых вод выступать в каче-
\end{abstract}




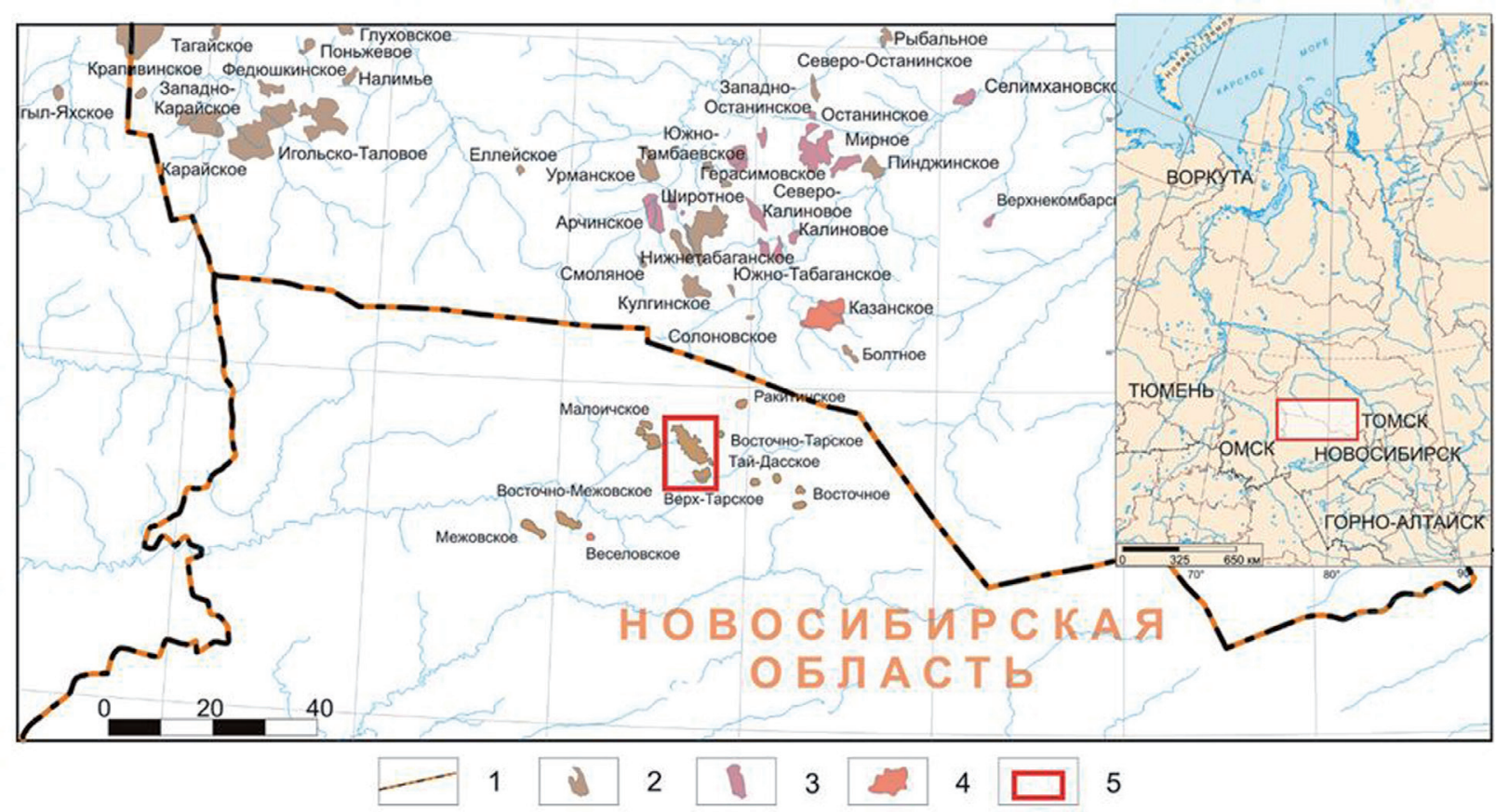

Рис. 1. Обзорная карта района исследований.

1 - административные границы; месторождения: 2 - нефтяные, 3 - нефтегазоконденсатные, 4 - газоконденсатные и газовые; 5 - местоположение района исследований.

Fig. 1. Overview map of the research area.

1 - administrative borders; fields: 2 - oil, 3 - oil - gas-condensate, 4 -gas-condensate and gas; 5 -area under investigation.

стве индикатора совокупных техногенных воздействий, и, его значимостью для оценки состояния окружающей среды и природных вод (Ахундов и др., 1967; Мехтиев и др., 1969; Никаноров, Сокирко, 1973; Порошин, Хайнак, 2000; Муляк, 2008; Порошин и др., 2011; Муляк и др., 2013).

Верх-Тарское нефтяное месторождение расположено в Северном районе северо-западной части Новосибирской области (рис. 1). Оно контролируется Верх-Тарской локальной структурой, выявленной сейсморазведочными работами МОВ в 1968-1969 гг. Поисковое бурение на структуре было начато в 1970 г. Открыла месторождение поисковая скв. № 1, расположенная в своде структуры. Разрез месторождения представлен отложениями юрского, мелового, палеогенового, неогенового и четвертичного возраста. На месторождении выявлено две залежи в продуктивных горизонтах

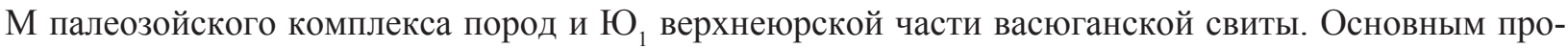
дуктивным горизонтом является Ю . По запасам нефти по результатам разведочных работ в 1974 г. залежь отнесена к категории средних. Коллектор сложен песчаниками и крупнозернистыми алевролитами с небольшими по мощности карбонатизированными прослоями. Залежь нефти пластовая, сводовая, с коллекторами порового типа.

Особенности гидрогеологического строения, гидродинамики, геотермического режима недр и гидрогеохимии нефтегазоносных отложений изучаемого региона рассмотрены нами ранее (Новиков и др., 2018 a, 2018 б, 2018 в, 2019а, 2019б; Садыкова и др., 2019). В рамках настоящей работы нами впервые обобщены результаты химико-аналитических исследований проб подтоварных вод, выполненных в лаборатории Верх-Тарского нефтяного промысла (более 4400 анализов). Дополнительно в ноябре 2018 и ноябре 2019 годов нами были проведены полевые работы, во время которых отобрано более 30 проб подтоварных вод из добывающего фонда скважин. Аналитические работы по изучению макро-, микроэлементного состава методами ICP-AES и ICP-MS были выполнены в Национальном исследовательском Томском политехническом университете.

Разработка залежи продуктивного горизонта Ю ведется с 2000 года. Обобщение геологической информации по материалам разведочного и эксплуатационного бурения, а также результатов 
сейсморазведочных работ 3D, проведенных в конце 90-х годов прошлого столетия, показало более сложный характер строения залежи. В связи с изменениями в геологической модели строения корректировалась технологическая схема разработки. На данный момент месторождение находится на IV стадии разработки (Новиков и др., 2019в). В настоящее время имеется много примеров увеличения длительности по времени разработки месторождения, находящего, как считалось ранее, на «завершающей стадии жизни». Результаты анализа гидрохимических материалов позволяют вносить изменения в технологическую схему и получать дополнительные объемы нефти за счет вовлечения в разработку «не работающих» участков залежи.

Изученные подземные воды однородны по своему химическому составу и принадлежат к хлоридному натриевому типу (по С.А. Щукареву) с величиной общей минерализации от 28 до 46 г/дм ${ }^{3}$ (Новиков и др., 2019г, 2019д). Подземные воды характеризуются нейтральными и слабощелочными значениями $\mathrm{pH}$, изменяющимися в интервале 7.4-7.9. В катионном составе доминирует $\mathrm{Na}^{+}$, концентрации которого достигают до 13-17 г/дм³ , а в анионном составе $-\mathrm{Cl}^{-}$, с содержаниями до 20-23 г/дм³. Концентрации основных солеобразующих макро- и микроэлементов напрямую зависят от величины их общей минерализации. Происходит закономерное увеличение содержаний $\mathrm{Cl}^{-}, \mathrm{Na}^{+}, \mathrm{Mg}^{2+}, \mathrm{Ca}^{2+}, \mathrm{K}^{+}$, микроэлементов: $\mathrm{Br}^{-}, \mathrm{I}^{-}, \mathrm{B}^{+}, \mathrm{NH}_{4}^{+}, \mathrm{Sr}^{2+}$ и других. В микроэлементном составе повышены содержания $\left(\mathrm{мг} /\right.$ дм$\left.^{3}\right): \mathrm{Sr}$ до 1328, Ва до 358, $\mathrm{Si}$ до 31.4, Li до 7.1 и $\mathrm{Mn}$ до 3.2. С ростом общей минерализации в растворе также накапливаются в следующих концентрациях тяжелые металлы (мкг/дм³): Zn до 370, Со до 70, $\mathrm{Cu}$ до 60, Cd до 40, Мо до 30, $\mathrm{Pb}$ до 20, Sn до 20, Ni до 10. Повышенным содержанием хрома до 0.1 мг/дм ${ }^{3}$ отличаются воды в скв. 507, тогда как фоновые значения ниже на математический порядок. Среди РЗЭ наибольшие концентрации отмечаются (мкг/дм³): у La до 20,8, Еu до 7.9, Gd до 1.8 и Ву до 0.57.

На гидрогеохимическое поле разрабатываемой залежи оказывает влияние в первую очередь агент заводнения, поступающий через сеть нагнетательных скважин, во-вторых техногенные жидкости после применения технологии гидроразрыва пласта и кислотной обработки призабойной зоны. На момент начала полномасштабной эксплуатации залежи пласта Ю щей минерализации подтоварных вод по фонду добывающих скважин варьировало в широком ин-
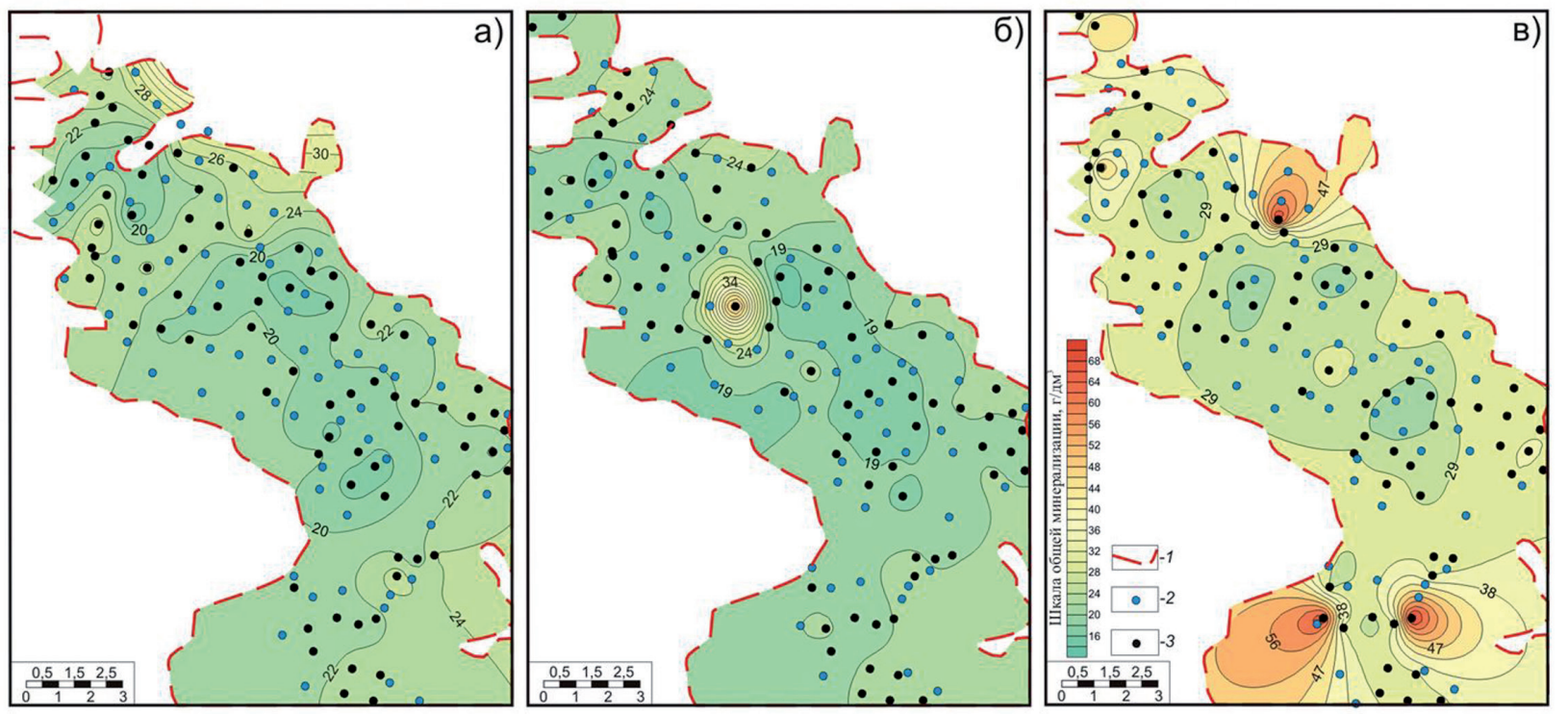

Рис. 2. Карты общей минерализации попутных (подтоварных) вод нефтяной залежи горизонта Ю Тарского месторождения по состоянию на сентябрь 2012 (а), октябрь 2013 (б) и июнь 2015 (в) года. 1 - контур нефтяной залежи; скважины: 2 - нагнетательные, 3 - добывающие.

Fig. 2. Maps of total mineralization of off-spec waters at the $\mathrm{Yu}_{1}$-horizon at the Verkh-Tarsk oil field by: September 2012 (a), October 2013 (b) and June 2015 (c).

1 - the oil reservoir outline; wells: 2 -injection, 3 - exploitation. 
тервале от 14 до 48 г/дм³, при среднем значении 28-30 г/дм³. Залежь пласта $Ю_{1}$ к настоящему времени практически полностью разбурена эксплуатационными скважинами. Общий фонд скважин на январь 2019 года составляет 175 единиц, из них 134 действующих. Добывающий фонд представлен 84 скважинами: 54 действующих, 25 наблюдательных и 5 простаивающих. Нагнетательный фонд, обеспечивающий работу системы поддержания пластового давления (ППД), насчитывает 91 скважину: 29 действующих, 26 наблюдательных и 36 простаивающих.

Поскольку попутные (подтоварные) воды - продукт смешения пластовых и закачиваемых в систему ППД флюидов возникает острая необходимость в их правильной диагностике для целей гидрогеохимического мониторинга добычи углеводородов, проведения трассерных исследований и т.д. Мониторинг гидрогеохимических показателей с 2009 по 2019 годы выявил множество аномалий. Для примера, рассмотрим изменение величины общей минерализации подтоварных вод по добывающему фонду скважин по состоянию на сентябрь 2012, октябрь 2013 и июнь 2015 года (рис. 2). Области более низких значений связаны с фронтом заводнения, контролируемого рядами нагнетательных скважин. Видно, что общий фон минерализации в 2012-2013 годах, как правило, не превышает 20 г/дм³ (рис. 2 а-б), что соответствует значениям для закачиваемых вод из апт-альбсеноманского водоносного комплекса. Аномальные значения выше 30-170 г/дм³ связаны с бурением новых скважин на соляном растворе $\left(\mathrm{CaCl}_{2}\right.$ и $\left.\mathrm{KCl}\right)$, а также проведением многостадийного гидроразрыва пласта.

Исследования проводились при финансовой поддержке проекта ФНИ № 0331-2019-0025 и РФФИ и Правительства Новосибирской области в рамках научного проекта № 19-45-540006.

\section{Литература}

1. Ахундов А.Р., Буряковский Л.А., Рачинский М.З., Мехтиев Т.Н. К вопросу контроля процесса заводнения газоконденсатных залежей по гидрохимическим зонам // Азербайджанское нефтяное хозяйство. 1967. № 1. C. 7-9.

2. Мехтиев Ш.Ф., Ахундов А.Р., Ворошилов Е.А. Влияние искусственного заводнения на гидрохимию нефтяного пласта. Баку: Маариф, 1969. 344 с.

3. Муляк В.В. Гидрогеохимия техногенеза при разработке нефтяных месторождений // Геология нефти и газа. 2008. № 3. С. 61-67.

4. Муляк В.В., Порошин В.Д., Гуляев В.Г., Маракасов Б.В. Гидрохимический мониторинг - инновационное направление анализа и контроля разработки нефтяных месторождений // Нефтяное хозяйство. 2013. № 3. C. 45-49.

5. Никаноров А.М., Сокирко Л.Е. Изучение процессов смешения вод нефтяных месторождений на модели пласта в условиях высоких давлений и температур // Нефтяное хозяйство. 1973. № 12. С. 36-40.

6. Новиков Д.А., Рыжкова С.В., Дульцев Ф.Ф., Черных А.В. О геотермической зональности нефтегазоносных отложений северо-западных районов Новосибирской области // Известия высших учебных заведений. Нефть и газ. 2018 а. № 5. С. 69-76. DOI: 10.31660/0445-0108-2018-5-69-76.

7. Новиков Д.А., Рыжкова С.В., Дульцев Ф.Ф., Черных А.В., Сесь К.В., Ефимцев Н.А., Шохин А.Е. Нефтегазовая гидрогеохимия доюрских комплексов южных районов Обь-Иртышского междуречья // Известия Томского политехнического университета. Инжиниринг георесурсов. 2018 б. Т. 329. № 12. С. 39-54. DOI: $10.18799 / 24131830 / 2018 / 12 / 19$.

8. Новиков Д.А., Рыжкова С.В., Шохин А.Е., Юдин С.В., Ефимцев Н.А., Черных А.В., Дульцев Ф.Ф. Результаты моделирования водно-газовых равновесий в пределах нефтегазоносных отложений Обь-Иртышского междуречья // Интерэкспо Гео-Сибирь. 2018 в. Т. 1. С. 77-84. DOI: 10.18303/2618-981X-2018-1-77-84.

9. Новиков Д.А., Шохин А.Е., Черников А.А., Дульцев Ф.Ф., Черных А.В. Геохимия водорастворенных газов нефтегазоносных отложений южных районов Обь-Иртышского междуречья // Известия высших учебных заведений. Нефть и газ. 2019 а. № 4. C. 70-81. DOI: 10.31660/0445-0108-2019-4-70-81.

10. Новиков Д.А., Дульцев Ф.Ф., Черных А.В., Рыжкова С.В. Гидродинамические особенности нефтегазоносных отложений южных районов Обь-Иртышского междуречья // Георесурсы. 2019 б. Т. 21. № 4. С. 85-94. DOI: $10.18599 /$ grs.2019.4.85-94.

11. Новиков Д.А., Павлова С.А., Кузнецов Д.Ю., Дульцев Ф.Ф., Черных А.В., Рыжкова С.В. Состояние разработки залежи $Ю_{1}$ Верх-Тарского нефтяного месторождения на январь 2019 года // Интерэкспо ГеоСибирь. 2019 в. Т. 2. № 1. С. 109-116. DOI: 10.33764/2618-981X-2019-2-1-109-116.

12. Новиков Д.А., Черных А.В., Дульцев Ф.Ф. Содержание редкоземельных элементов в подземных водах 
верхнеюрских отложений Верх-Тарского нефтяного месторождения (Западная Сибирь) // Интерэкспо Гео-Сибирь. 2019. Т. 2. № 1. С. 141-148. DOI: 10.33764/2618-981X-2019-2-1-141-148.

13. Новиков Д.А., Шохин А.Е., Черных А.В., Дульцев Ф.Ф. Формы миграции химических элементов в подземных водах горизонта Ю Верх-Тарского нефтяного месторождения (юг Западной Сибири) // Труды Ферсмановской научной сессии ГИ КНЦ РАН. 2019 д. № 16. С. 448-453. DOI: 10.31241/FNS.2019.16.091.

14. Садыкова Я.В., Фомин М.А., Рыжкова С.В., Новиков Д.А., Дульцев Ф.Ф., Черных А.В. Прогноз нефтегазоносности юрских и палеозойских отложений южных районов Западно-Сибирского бассейна // Известия Томского политехнического университета. Инжиниринг георесурсов. 2019. Т. 330. № 9. С. 114-127. DOI: $10.18799 / 24131830 / 2019 / 9 / 2260$.

15. Порошин В.Д., Гуляев В.Г., Радченко М.В., Мельничук И.С., Маракасов Б.В. Возможности гидрохимического мониторинга при анализе и контроле разработки нефтяных месторождений (на примере Тимано-Печорской провинции) // Территория нефтегаз. 2011. № 11. С. 62-67.

16. Порошин В.Д., Хайнак В.П. Взаимодействия в системе порода-вода при разработке залежей нефти в подсолевых и межсолевых отложениях (на примере Припятского прогиба) // Литология и полезные ископаемые. 2000. № 5. С. 544-553. 